\title{
Macular hole surgery under retrobulbar local anesthesia increases visual acuity
}

\author{
Gilbert WS Simanjuntak*, Golda A M Simanjuntak*, and Reinne Natali Christine*
}

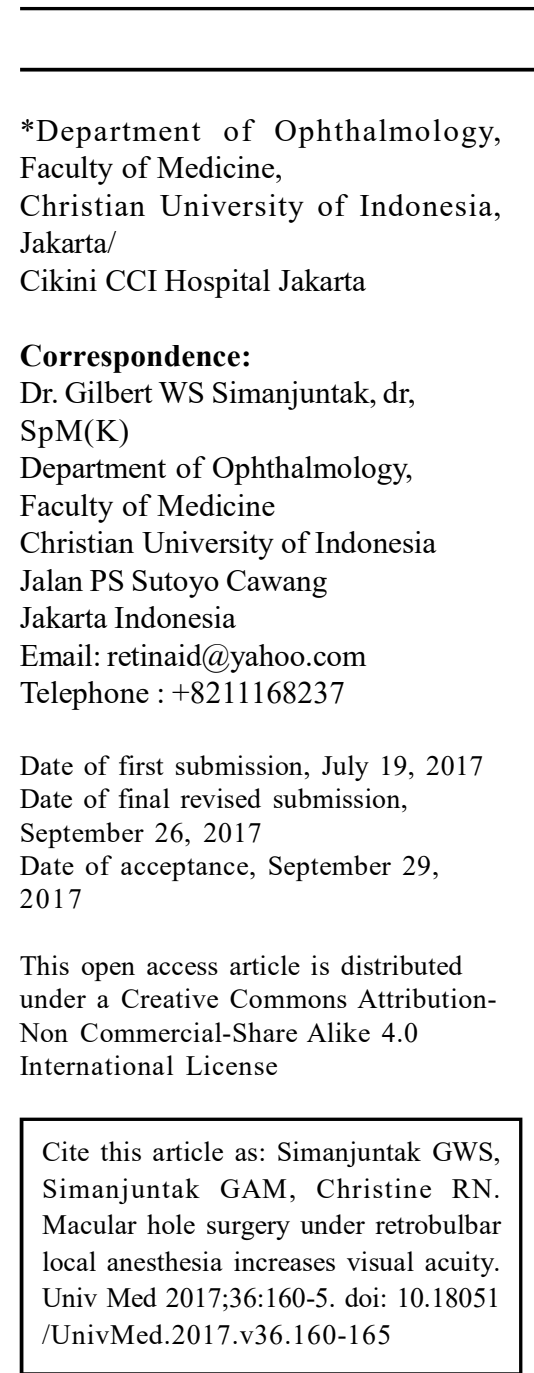

\section{ABSTRACT}

\section{BACKGROUND}

Macular hole surgery can be done under general or local anesthesia, and general anesthesia is still the standard procedure. The objective of this study was to investigate the results of macular hole surgery under local anesthesia.

\section{METHODS}

A retrospective study on medical records of patients who had undergone macular hole surgery under local anesthesia. Funduscopic examination of macular hole had been performed and all other diseases with deterioration of visual acuity eliminated. Surgery was performed under retrobulbar local anesthesia, using $2 \mathrm{ml}$ of $2 \%$ lidocaine mixed with $3 \mathrm{ml}$ bupivacaine in one syringe. Vitreous tamponade used $20 \%$ sulfur hexafluoride $\left(\mathrm{SF}_{6}\right)$. Demographic and clinical characteristics, visual acuity before and after surgery, and improvements that occurred were assessed.

\section{RESULTS}

No significant interruption occurred during surgery. Mean age of the patients was $53.89 \pm 13.3$ years (22-74 years), with mean duration of symptoms of $48.83 \pm 100.51$ weeks (1-560 weeks). The patients comprised 20 males (55.6\%) and 16 females (44.4\%). There were improvements in visual acuity after surgery in 31 patients $(86.1 \%)$, the rest $(13.9 \%)$ had identical or lower visual acuity after surgery. A total of 20 patients $(55.6 \%)$ had postoperative visual acuity of $6 / 18$ or better. Initial mean preoperative visual acuity was $0.08 \pm 0.08(0.01-0.29)$ and improved after the surgery to $0.38 \pm 0.26(0.00-1.00)$, the improvement being statistically significant $(\mathrm{p}=0.000)$.

\section{CONCLUSION}

Retrobulbar anesthesia is an effective and safe method in macular hole surgery. Macular hole surgery can be done well under local anesthesia, and visual acuity improved significantly.

Keywords: Macular hole, anesthesia, blindness, visual acuity, vitrectomy 


\section{INTRODUCTION}

Macular holes may occur spontaneously, presumably due to a dehiscence on the macular surface. $^{(1)}$ Other possible causes are trauma, cystoid macular edema, and abnormal macular traction such as in vitreomacular traction syndrome, epiretinal membrane or tractional retinal detachment. ${ }^{(2)}$ Usually a macular hole is accompanied by localized retinal detachment around the hole, and a tiny retinal operculum attached to the vitreous that exerts traction upon it. A macular hole can be directly seen and diagnosed at fundoscopy. ${ }^{(1,2)}$

Macular hole management is by surgery. Before 1991, the disease could not be resolved and ended with visual impairment. After Kelly and Wendel (2) reported the results of vitrectomy surgery with a gas tampon, which succeeded in closing the macular hole, the experts competed to report good results after vitrectomy. Vitrectomy is generally done under general anesthesia.

Local anesthesia techniques for vitreoretinal surgery include retrobulbar, subtenon, peribulbar, and topical anesthesia. ${ }^{(3)}$ Although the advantages of local anesthesia are well known and include more rapid return to ambulation for the patient, ability to perform the surgery as an outpatient procedure, avoidance of complications of general anesthesia, and quicker surgery, it has been the subject for some controversy. ${ }^{(4)}$

In Indonesia, vitrectomy under local anesthesia was reported to be a standard in one of the hospitals. ${ }^{(5)}$ Operation under local anesthesia will make for faster and safer patient mobilization. ${ }^{(6)}$ Patients' difficulty to sleep on their stomach for at least a week is very burdensome, especially for those who have problems with the spine. As an alternative to gas, some surgeons have recommended silicone oil. Each technique has its advantages and disadvantages. The visual improvement after surgery is the more important issue and also the goal. ${ }^{(3,6)}$
However, the visual experience of the patients while under local anesthesia was not well recognized or understood until a few years ago. Most patients undergoing vitreous surgery under local anesthesia experience a variety of intraoperative visual sensations. ${ }^{(7)}$ The purpose of this study was to investigate the results of macular hole surgery under local anesthesia.

\section{METHODS}

\section{Research design}

This was a retrospective analytic study by collecting medical records of patients who underwent macular hole surgery under local anesthesia at Cikini CCI Hospital over a period of 12 years $(2004-2015)$.

\section{Ophthalmologic examination}

Regular ophthalmologic examinations were performed which included examination of corneal clarity, especially of the central area, lens clarity; iris examination and to find anterior and posterior synechiae if any. Visual acuity (VA) before surgery was checked and pre operative best-corrected VA of all patients was $0.08 \pm$ 0.08 . The posterior segment examination was performed thoroughly and carefully, looking at the conditions of the peripheral retina and the macula specifically using a 90D lens with magnification and estimating the size of the hole by comparing with the caliber of the veins coming out of the optic nerve (N. II); looking at the condition of the optic nerve, and examining the intraocular pressure (IOP). As far as possible, the macular hole size was predicted clinically by using optical coherence tomography (OCT). If the hole was calculated to be more than 600 microns in diameter, then the operation was canceled or if the patient still requested surgery then the less promising postoperative vision prognosis was explained.

\section{Surgery for macular hole}

The operation was performed under retrobulbar local anesthesia, using $2 \mathrm{~mL}$ of $2 \%$ 
lidocaine mixed with $3 \mathrm{~mL}$ of bupivacaine in one syringe. When necessary, an additional $2 \mathrm{~mL}$ of lidocaine was used for subtenon injection during surgery towards the optic nerve. The pupils were dilated maximally by dripping $1 \%$ tropicamide (Mydriatil) and 10\% Efrisel at intervals of 10 minutes for a minimum of 3 times, before surgery.

Vitrectomy was done as cleanly as possible. If there was a retinal tear or peripheral lesion, a laser was performed. Internal limiting membrane (ILM) staining was performed with trypan blue in an air tampon, and was left for one minute then the ILM peeled with forceps. 20\% sulfur hexafluoride $\left(\mathrm{SF}_{6}\right.$ ) gas was given after surgery as vitreous tamponade. After surgery, the patient's sleeping position was tilted contralaterally toward the unoperated eye for 2 days, and from the third day until the seventh was made completely downward except for eating and toilet activities.

\section{Measurements}

Any important clinical findings obtained during and after surgery were recorded. Patients were instructed to make follow up visits at 1,7 and 14 days after surgery in the first month. Afterwards every 1-2 months for the first 6 months. Postoperative treatment consisted of topical steroids and antibiotics that were gradually reduced for 1 month, and oral antiglaucoma medications for 2 weeks. Tamponade used was $\mathrm{SF}_{6} 20 \%$ gas. A VA and intraocular pressure examination before surgery and at every postoperative visit was made by opticians who were unaware of the type of surgery or patient illness. Patients who experience cataracts, will be operated two months after macular surgery. Only patients with a full threemonth follow-up were included in this study. Subjects were not included if they had obscured media or optic nerve damage.

\section{Statistical analysis}

Independent t-test was used to analyze the data. Normality of the data was tested with the
Kolmogorov-Smirnov test, at $95 \%$ confidence interval.

\section{Ethical clearance}

Informed consent was obtained after the patients clearly understood the risks involved, including the anatomical and functional success rates and the actions required if a second operation was required. The Christian University of Indonesia Institutional Ethics Committee granted approval for this study following the tenets of the Declaration of Helsinki (No. 17/ $\mathrm{Pen} / \mathrm{KM} / 2017$ ).

\section{RESULTS}

There were 48 medical records of patients who had undergone macular hole surgery at Cikini CCI Hospital from 2004-2015. A total of 12 medical records were not evaluated due to incomplete records, or incomplete follow up visit for three months. A total of 36 medical records were included, and all had undergone macular hole surgery under local anesthesia. During surgery, there was no additional anesthesia, either subtenon, subconjunctival or retrobulbar injection. Based on the surgical reports, there were no significant complaints such as patient discomfort during surgery, or other complaints that interfered with surgery, such as inability of patients to calm down, shortness of breath, frequent movements, or fear.

The operation was performed with $20 \mathrm{G}$ instrument and the sclerotomy incision was closed with one stitch of 8.0 Vycril. All patients were filled with $\mathrm{SF}_{6} 20 \%$ gas tamponade, no patients had spinal disorders, so that they could sleep on their stomach for a minimum of 1 week, and all patients made complete follow up visits. The subjects' mean age was $53.89 \pm 13.30$ years (22-74 years), with a mean macular hole duration of $48.83 \pm 100.51$ weeks (1-560 weeks). The subjects consisted of 20 males (55.6\%) and 16 females (44.4\%). There was VA improvement after surgery in 31 patients $(86.1 \%)$, in the remaining $(13.9 \%)$ the VA was the same or 
Table 1. Characteristics of patients undergoing macular hole surgery under local anesthesia $(n=36)$

\begin{tabular}{lc}
\hline Characteristic & \\
\hline Sex (n,\%) & \\
Male & $20(55.6)$ \\
Female & $16(44.4)$ \\
Age (years) & $53.89 \pm 13.30$ \\
Duration of symptoms (weeks) & $48.83 \pm 100.51$ \\
Visual acuity (VA) & \\
$\quad$ Initial VA & $0.08 \pm 0.08$ \\
Final VA & $0.38 \pm 0.26$ \\
p value & 0.001 \\
\hline
\end{tabular}

worse after surgery. A total of 20 patients $(55.6 \%)$ had a VA of $6 / 18$ or better after surgery. The pre-operative VA was $0.08 \pm 0.08(0.01$ $0.29)$, and improved after surgery to $0.38 \pm 0.26$ ( 0.00 to 1.00$)$, statistically significant $(\mathrm{p}=0.00)$ (Table 1).

As a detailed illustration, a funduscopic view and an optical coherence tomography (OCT) examination of one patient before and after the surgery, is presented. It appeared that the hole and localized retinal detachment becomes closed and attached, respectively, after surgery. There was improvement in vision after surgery (Figure 1).

\section{DISCUSSION}

Retinal surgery, including macular hole surgery, is generally done under general anesthesia. Only a small portion of the center serves the surgery under local anesthesia as the primary choice. There are several commonly used local anesthetic agents. Bupivacaine has the advantage of a block effect of long duration, but its onset is slow when used singly under anesthesia. ${ }^{(8)}$ Although lidocaine has a rapid onset of analgesia and akinesia, the effect is shorter. ${ }^{(9)}$ Therefore, a mixture of balanced volumes of bupivacaine and lidocaine is often used to achieve rapid onset of analgesia with prolonged effect. This effect may be extended during surgery under local anesthesia by subtenon injection, or during general anesthesia in pediatric patients. ${ }^{(10,11)}$

The study of Zhou et al.(9) found that the combination of lidocaine and bupivacaine has a time of onset of analgesia of $101.51 \pm 56.94$ minutes and onset of akinesia of $141.00 \pm 62.69$ minutes. Local anesthesia is also an alternative to general anesthesia in other medical procedures. This has been reported in cardiac procedures, ${ }^{(12)}$ cerebral biopsy, ${ }^{(13)}$ and surgery for umbilical hernias. ${ }^{(6)}$ Related to the cooperativeness of the patients in ocular surgery, pain perception is positively influenced by female gender, rural place of residence, younger age of patient, and lower preoperative visual acuity. ${ }^{(14)}$ Recovery time under local anesthesia was almost insignificant compared to general anesthesia, and this recovery time may differ between drugs used, ${ }^{(15)}$ or procedures. $^{(16)}$ One of the disadvantages of retrobulbar injections under local anesthesia is the possibility of accidentally penetrating the eyeball. ${ }^{(17)}$
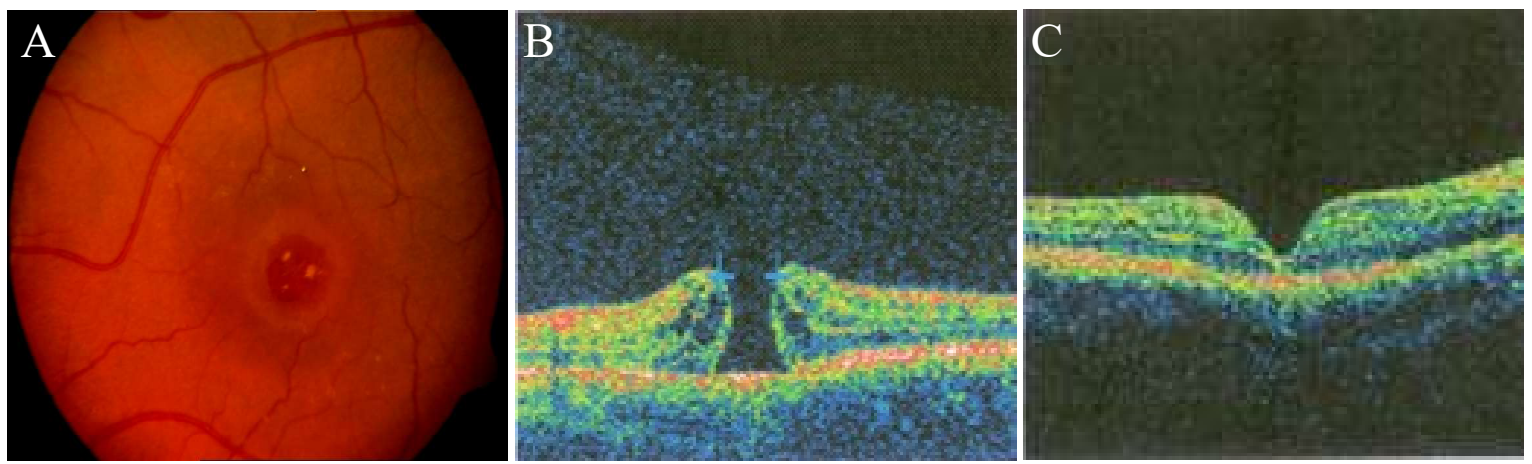

Figure 1. (A). Funduscopic view with macular hole, accompanied by a localized retinal detachment around the macula; (B). OCT results clearly show the full thickness macular hole, VA of 0.1 ; (C). The operating result shows the macular hole closed, with improved VA, 0.5 
Fear of the patient moving spontaneously during surgery, uneasiness and pain was not found in the present surgical report records. The possibility of such disturbance maybe existed but was not to be regarded either as complicating the operation or as significant, and therefore not recorded. Another possibility is that the patients had received complete information, so that they were quieter on the operating table. This may be seen from the $86.1 \%$ improvement of vision after surgery. These improvements were significant when compared with the results of existing operations in other countries, ranging from 42 to $100 \%$, with a mean of $65.2 \%{ }^{(18)}$ In the present study it can be seen that $55.6 \%$ of subjects obtained a visual acuity $6 / 18$ or better after surgery. In comparison, in the study by $\mathrm{Chu}$ et al., ${ }^{(8)}$ the surgery was a combination of pars plana vitrectomy, inverted internal limiting membrane flap technique and intraocular gas tamponade for macular hole-induced retinal detachment, the resulting retinal reattachment rate was $100 \%$ and the rate of macular hole closure was $73.3 \%$. The mean of best-corrected visual acuity (BCVA), converted to the logarithm of the minimal angle of resolution ( $\log$ MAR), improved from $1.73 \pm$ 0.69 to $1.16 \pm 0.51 \operatorname{logMAR}(\mathrm{p}<0.05)$. In the present study the number of male and female subjects was comparable, whereas in other study settings, the females were almost twice the number of males. ${ }^{(18)}$ Possible demographic factors in Indonesia, where patients in Cikini CCI Hospital generally come from areas outside Java are also worth considering. The current prevalence of blindness in Indonesia of $3.2 \%$ is in line with rapid assessments of avoidable blindness (RAAB) research results in several provinces. ${ }^{(19)}$ Among these cases of blindness, there was blindness due to retinal disease, such as macular diseases. In comparison, it has been estimated that there are new cases of retinal disorders of 17,500 - 25,000 per year. $^{(20,21)}$ This was evidenced by the results above, that macular surgery under local anesthetic can be performed successfully, resulting in VA improvement of $86.1 \%$. Our study was limited by the small sample size and retrospective nature. A multivariate study with a larger number of patients is needed to confirm our findings.

\section{CONCLUSION}

This study demonstrated that macular hole surgery can be done under local anesthesia with a significant visual acuity improvement.

\section{CONFLICT OF INTEREST}

None. No authors have any financial/ conflicting interests to disclose.

\section{ACKNOWLEDGEMENT}

The authors wish to express their gratitude to the Faculty of Medicine, Christian University of Indonesia, for supporting this study.

\section{CONTRIBUTORS}

GWSS contributed to the concept and design of the study, data analysis and/or interpretation. GAMS contributed to data acquisition and drafting. RNC revised the manuscript critically for important intellectual content. All authors read and approved the final manuscript.

\section{REFERENCES}

1. Johnson WM. Perifoveal vitreous detachment and its macular complication. Trans Am Ophthalmol Soc 2005;103:537-67.

2. Liu W, Grzybowski A. Current management of traumatic macular hole. J Ophthtalmol 2017;17:1 8.

3. Seidenari P, Santin G, Milani P, et al. Peribulbar and retrobulbar combined anesthesia for vitreoretinal surgery using ropivacaine. Eur J Ophthalmol 2006;16:295-9.

4. Chan VM, Loo AVP, Tam BSM, et al. Topical anesthesia in posterior vitrectomy. Retina 2000; 20:563-4.

5. Simanjuntak GWS. Surgical result of pseudophakic retinal detachment in Cikini CCI 
Hospital-School of Medicine Christian University of Indonesia. J Ophthalmol Indones 2009; 7:52-5.

6. Jairam AP, Kaufmann R, Muysoms F, et al. The feasibility of local anesthesia for the surgical treatment of umbilical hernia: a systematic review of the literature. Hernia 2017;21:223-31.doi: 10.1007/s10029-017-1577-z.

7. Prasad N, Kumar CM, Patil BB, et al. Subjective visual experience during phacoemulsification cataract surgery under sub-Tenon's block. Eye 2003;17:407-9.

8. Chu B, Tsang S, Yuen C. A combination of pars plana vitrectomy, inverted internal limiting membrane flap technique and intraocular gas tamponade for macular hole-induced retinal detachment. HKJ Ophthalmol 2016;20:109-13.

9. Zhou Y, Tong Y, Wang Y, et al. A prospective, randomised, double-masked comparison of local anaesthetic agents for vitrectomy. Br J Ophthalmol 2017;0:1-6. doi:10.1136/bjophthalmol-2016309780.

10. Chhabra A, Sinha R. Subramaniam R, et al. Comparison of sub-Tenon's block with i.v. fentanyl for paediatric vitreoretinal surgery. $\mathrm{Br} \mathrm{J}$ Anaesth 2009; 103:739-43.

11. Ghai B, Ram J, Makkar JK, et al. Subtenon block compared to intravenous fentanyl for perioperative analgesia in pediatric cataract surgery. Anesth Analg 2009;108:1132-8.

12. Jabbar A, Khurana A, Mohammed A, et al. Local versus general anesthesia in transcatheter aortic valve replacement. Am J Cardiol 2016;1;118:171216.

13. Quick-Weller J, Konczalla J, Duetzmann S, et al. General anesthesia versus local anesthesia in stereotactic biopsies of brain lesions: a prospective randomized study. World Neurosurg 2017;105:16-20.
14. Omulecki W, Laudanska-Olszewska I, Synder A. Factors affecting patient cooperation and level of pain perception during phacoemulsification in topical and intracameral anesthesia. Eur J Ophthalmol 2009;19:977-83.

15. Mir AH, Shah NF, Din MU, et al. Effectiveness of sodium thiopentone, propofol, and etomidate as an ideal intravenous anesthetic agent for modified electroconvulsive therapy. Saudi J Anaesth 2017;11:26-31. doi: 10.4103/1658-354X. 197339.

16. Jain RA, Shetty AN, Oak SP, et al. Effect of avoiding neuromuscular blocking agents during maintenance of anaesthesia on recovery characteristics in patients undergoing craniotomy for supratentorial lesions: A randomised controlled study. Indian J Anaesth 2017;61:42-7. doi: 10.4103/0019-5049.198408.

17. Wadood AC, Dhillon B, Singh J. Inadvertent ocular perforation and intravitreal injection of an anesthetic agent during retrobulbar injection. J Cataract Refract Surg 2002;28:562-5.

18. Simanjuntak GWS. Surgical approach for macular diseases. Makassar: Pertemuan Ilmiah Tahunan Dokter Spesialis Mata;2008.

19. Das T, Ackland P, Correia M, et al. Is the 2015 eye care service delivery profile in Southeast Asia closer to universal eye health need! Int Ophthalmol 2017;2: 1-10. doi: 10.1007/s10792-0170481-y.

20. Gupta OP, Benson WE. The risk of fellow eyes in patients with rhegmatogenous retinal detachment. Curr Opin Ophthalmol 2005;16:1758.

21. Mitry D, Charteris DG, Fleck BW, et al. The epidemiology of rhegmatogenous retinal detachment: geographical variation and clinical associations. Br J Ophthalmol 2010;94:678-84. 